\title{
Effect of some fungicides against the growth inhibition of Sclerotinia sclerotiorum mycelial compatibility groups
}

\author{
Alireza Dalili*, Saeed Bakhtiari ${ }^{2}$, Hossein Barari ${ }^{1}$, Majid Aldaghi ${ }^{1}$ \\ ${ }^{1}$ Department of Plant Protection Research, Mazandaran Agricultural and Natural Resources Research and Education Center, \\ AREEO, P.O. Box 48175-556, Sari, Iran \\ ${ }^{2}$ Department of Plant Protection Research, Damghan Azad University, P.O. Box 36716-39998, Damghan, Iran
}

Received: May 27, 2015

Accepted: October 13, 2015

\begin{abstract}
Sclerotinia sclerotiorum (Lib.) de Bary, the causal agent of Sclerotinia stem rot, is one of the most important pathogens of Brassica napus L. in northern Iran. In this study, 13 mycelial compatibility groups (MCGs) of the fungus were identified among 31 isolates sampled from four regions of Mazandaran province, Iran. Effective fungicides are useful in the integrated management of the disease. So, the effect of tebuconazole, propiconazole, cyproconazole, and Rovral-TS at five doses $(0.0001,0.001,0.01,0.1$, and 1 $\mathrm{ppm}$ ) was studied on the growth inhibition of S. sclerotiorum as in vitro tests. Maximum inhibition (100\%) of S. sclerotiorum mycelial growth was obtained by the highest dose ( $1 \mathrm{ppm})$ of all tested fungicides, as well as by the doses of 0.1 and 0.01 ppm of propiconazole, cyproconazole, and tebuconazole. In this investigation, the reaction of S. sclerotiorum isolates belonging to different MCGs was evaluated against tebuconazole, propiconazole, cyproconazole, and Rovral-TS at their $\mathrm{EC}_{50}$ ranges. The results revealed that there was high variation of S. sclerotiorum MCGs against different fungicides. The inhibition percentage varied between $4.29 \%$ and $71.72 \%$.
\end{abstract}

Key words: Brassica napus, fungicide, mycelial compatibility groups (MCGs), Sclerotinia sclerotiorum

\section{Introduction}

Sclerotinia stem rot (SSR) of Brassica napus L., caused by Sclerotinia sclerotiorum, is an important disease worldwide. The disease leads to significant losses of seed quantity and quality (Zhao et al. 2004). Sclerotinia sclerotiorum is one of the most non-specific plant pathogens (Purdy 1979) and attacks over 400 plant species in 75 families (Boland and Hall 1994).

Several methods have been developed for the management of SSR, including cultural, biochemical, and chemical means (Garg et al. 2008). Different studies were carried out on the chemical control of S. sclerotiorum. The results showed that method is one of the most important means for SSR management. Bradley et al. (2006) studied the efficacy of different fungicides against $S$. sclerotiorum and the results indicated that those fungicides that consistently reduced SSR incidence compared with an untreated control, were azoxystrobin, benomyl, boscalid, iprodione, prothioconazole, tebuconazole, thiophanate-methyl, trifloxystrobin, and vinclozolin. Duan et al. (2013) investigated the effect of fludioxonil on the morphological and physiological characteristics of S. sclerotiorum. The results revealed fludioxonil had a high level of inhibition on the mycelia growth of the fungus.

Chemical fungicides have been used against plant pathogenic fungi. Frequent usage of the synthetic fungicides leads to the development of a resistant population of the fungi as well as environmental and human health hazards (Lobato et al. 2010).
The effect of benomyl was investigated against S. sclerotiorum and the results revealed the growth of isolates from 13 fields, was inhibited by low concentrations of benomyl $\left(\mathrm{EC}_{50}<8 \mathrm{mg} \cdot \mathrm{l}^{-1}\right)$, but two isolates exhibited a resistant reaction $\left(\mathrm{EC}_{50}>200 \mathrm{mg} \cdot \mathrm{l}^{-1}\right)$. Resistant isolates were obtained only from two canola fields in which reduced efficacy of benomyl were suspected (Gossen et al. 2001).

The efficacy of carbendazim (MBC) against S. sclerotiorum during the 2006 to 2008 time period was studied. The results showed that MBC resistant S. sclerotiorum populations were widespread throughout the Jiangsu Province with a resistance frequency of $29.54 \%$ among 1,786 collected isolates. The resistance frequencies differed among sampled cities, ranging from $3.1 \%$ to $54.9 \%$ (Ma et al. 2009).

The dicarboximide class (iprodione, vinclozolin, and procymidone) has been used since the mid-1970s to mainly control the fungi of the genera Botrytis, Sclerotinia, and Monilinia. The fungicide-resistant variants frequently appear in laboratory cultures. After about three years of intensive use of the fungicide, resistant strains were also detected in the field (Brent and Hollomon 2007). The reaction of the dicarboximide fungicide iprodione, was investigated against 50 historic populations (collected in 2001) and 111 populations collected in 2007-2008. The results showed that $\mathrm{EC}_{50}$ values of these historic population isolates to iprodione ranged from 0.163 to $0.734 \mu \mathrm{g} \cdot \mathrm{ml}^{-1}$ with a mean of $0.428 \mu \mathrm{g} \cdot \mathrm{ml}^{-1}$. The $\mathrm{EC}_{50}$ values of these 
111 isolates from rapeseed fields with $4-5$ years of iprodione application, ranged from 0.117 to $0.634 \mu \mathrm{g} \cdot \mathrm{ml}^{-1}$ (Liu et al. 2009). Cross resistance to benomyl and iprodione was also detected (Attanayake et al. 2013).

Sterol biosynthesis inhibitors, such as tebuconazole, propiconazole, and cyproconazole, are a large class of fungicides made up of three distinct groups: the sterol C-14 demethylation inhibitors (DMIs), amines, and hydroxyanilides. It was in the 1970s that DMIs were first used. There were very few reports of DMI resistance in 1982 (Brent and Hollomon 2007).

Mycelial compatibility/incompatibility is a macroscopic assay of the self-/non-self recognition system controlled by multiple loci (Glass and Kaneko 2003). There are well-characterized interaction zones which occur between vegetatively incompatible isolates of $S$. sclerotiorum. It has been suggested that mycelial compatibility groups (MCGs) represent genetically dissimilar individuals and each MCG is a particular genotype (Kohn et al. 1990).

The population variability of Iranian strains of S. sclerotiorum was studied by mycelial compatibility grouping. Among 186 tested isolates, 26 MCGs were identified (Irani et al. 2011). Sclerotinia sclerotiorum is one of the most important pathogens of B. napus in the Gilan, Mazandaran, and Golestan provinces situated in northern Iran. The effect of different fungicides against the pathogen and the reaction of its MCGs were evaluated in this study.

\section{Materials and Methods}

\section{Fungal isolation}

During the 2012-2013 time period, sampling was conducted in rapeseed farms at Sari, Ghaemshar, Jouibar, and Babolsar regions of northern Iran. In each farm, five points in an " $\mathrm{M}$ " form were selected for sampling. Small pieces of infected tissues were sterilized in $0.8 \%$ sodium hypochlorite for $1 \mathrm{~min}$, and then rinsed 3-4 times with distilled water. Surface-sterilized tissues were transferred to Potato Dextrose Agar (PDA) medium. The cultures were incubated at $22 \pm 1^{\circ} \mathrm{C}$ in darkness for three days and fungus purification was carried out by using the hyphal tip culture technique.

\section{Mycelial compatibility groups}

The isolates were paired in all possible combinations on PDA, amended with $75 \mu$ of Wilton's red food coloring (Wilton Corp., USA) per liter of culture medium (Schafer and Kohn 2006). The test was carried out in three replicates. All pairings were evaluated 7 and 14 days after incubation in the dark at $22 \pm 1^{\circ} \mathrm{C}$.

Assessments of compatibility were based on the fusion of the two hyphal colonies, and incompatibility was reflected by the formation of a strip or aerial mycelia at the interaction zone. Mycelial incompatibility can also be recognized by the formation of a dark red line along the interaction zone in media supplemented with the red dye (Kohli et al. 1992).

\section{Effect of selected fungicides on the growth of Sclerotinia sclerotiorum}

The effect of tebuconazole (250 EW), propiconazole (250 EC), cyproconazole (100 SL), and Rovral TS (52.5\% WP) on the growth rate of $S$. sclerotiorum was evaluated on PDA (Grover and Moore 1962). The fungicides were separately added to PDA (at $45^{\circ} \mathrm{C}$ ) to give a final concentration of $0.0001,0.001,0.01,0.1$, and $1 \mathrm{ppm}$, and the resulting media were poured in petri dishes $(8 \mathrm{~cm}$ in diameter). Water was added to the medium in the control plates. Then, inoculum discs (5 $\mathrm{mm}$ in diameter) from the margin of culture which had been growing for two days of a randomly selected S. sclerotiorum isolate (No. 4), was placed in the center of Petri plates containing PDA amended with fungicide. Each treatment was tested on four plates as replications. The plates were incubated at $22 \pm 1^{\circ} \mathrm{C}$. After two days (when the fungus had grown on control plates close to the margin of plate), radial growth of the fungus was recorded for each plate. The percentage of fungal growth inhibition was calculated according to the Pandey et al. (1982) formula:

Growth inhibition $\%=[$ (growth in the control - growth in the sample)/growth in the control] $\times 100$.

Data was statistically analyzed using an MSTAT-C program with the factorial experiment as the completely randomized design (CRD). Inhibition of radial mycelial growth was examined using analysis of variance (ANOVA). The Duncan's Multiple Range Test (DMRT) was employed to determine significant $(p<0.01)$ differences among mean values.

\section{Calculation of fungicide $\mathrm{EC}_{50}$ and the reaction of Sclerotinia sclerotiorum MCGs to the fungicides}

To calculate $\mathrm{EC}_{50}$, the fungicides were added to PDA (at $45^{\circ} \mathrm{C}$ ) to give a final concentration of $0.001,0.002,0.004$, 0.006 , and $0.008 \mathrm{ppm}$ for tebuconazole, propiconazole, cyproconazole, and 0.001, 0.01, 0.1 and 1 ppm for RovralTS. The resulting media were poured in Petri dishes ( $8 \mathrm{~cm}$ in diameter). Then, inoculum disc ( $5 \mathrm{~mm}$ in diameter) from the culture margin of S. sclerotiorum (isolate No. 4) which had been growing for two days, was placed in the center of Petri plates containing PDA amended with fungicide. Each treatment was tested on three plates as replications. The plates were incubated in $22 \pm 1^{\circ} \mathrm{C}$. After two days (when the fungus had grown on control plates close to the margin of plate), the radial growth of S. sclerotiorum was measured for each plate. The percentage of fungal growth inhibition was calculated according to the Pandey et al. (1982) formula. After calculating the percent of growth inhibition, the $\mathrm{EC}_{50}$ of each fungicide was determined by linear regression. Then, the effect of each fungicide at its $\mathrm{EC}_{50}$ concentration was investigated on the growth rate of 13 MCGs (one isolate per MCG as its representative). Each treatment was tested on three plates as replications. The percentage of fungal growth inhibition was calculated. By means of the MSTAT-C program, data was statistically analyzed employing a completely randomized design (CRD). The procedure for the mean comparisons was similar to that used beforehand. 
Table 1. Sclerotinia sclerotiorum strains isolated from different locations and grouped into mycelial compatibility groups (MCGs)

\begin{tabular}{|c|c|c|c|c|c|c|c|c|}
\hline Isolate No. & Location & MCGs & Isolate No. & Location & MCGs & Isolate No. & Location & MCGs \\
\hline 1 & Sari & 1 & 12 & Babolsar & 5 & 23 & Sari & 9 \\
\hline 2 & Jouybar & 1 & 13 & Babolsar & 5 & 24 & Jouybar & 10 \\
\hline 3 & Jouybar & 1 & 14 & Babolsar & 5 & 25 & Qaemshahr & 10 \\
\hline 4 & Sari & 2 & 15 & Qaemshahr & 6 & 26 & Babolsar & 11 \\
\hline 5 & Sari & 3 & 16 & Babolsar & 6 & 27 & Babolsar & 11 \\
\hline 6 & Sari & 3 & 17 & Qaemshahr & 7 & 28 & Babolsar & 11 \\
\hline 7 & Jouybar & 3 & 18 & Qaemshahr & 8 & 29 & Babolsar & 11 \\
\hline 8 & Jouybar & 3 & 19 & Jouybar & 9 & 30 & Babolsar & 12 \\
\hline 9 & Jouybar & 3 & 20 & Jouybar & 9 & 31 & Babolsar & 13 \\
\hline 10 & Sari & 4 & 21 & Jouybar & 9 & & & \\
\hline 11 & Qaemshahr & 5 & 22 & Sari & 9 & & & \\
\hline
\end{tabular}

\section{Results}

\section{Mycelial compatibility groups}

In the present study, 31 strains of S. sclerotiorum were isolated from 15 rapeseed-infected fields from four cities in northern Iran (Table 1). Thirteen mycelial compatibility groups were identified among the 31 isolates. Six isolates were established as independent MCGs. This means that each isolate was compatible only with itself. Mycelial compatibility groups 3, 9, 5, 11, 1, 6, and 10 consisted of 5, 5, 4, 4, 3, 2, and 2 isolates, respectively (Table 1). Distribution of the MCGs differed within the four sampled regions. In addition, the MCG analysis of S. sclerotiorum populations indicated the presence of a heterogeneous mix of MCGs in a given location (Table 1). As shown in figure 1, the frequency of the MCGs identified in northern Iran ranged from 3.2 and 16.1\%.

\section{Effect of selected fungicides on the growth of Sclerotinia sclerotiorum}

To study the efficacy of selected fungicides on the growth inhibition of S. sclerotiorum, radial mycelia growth in two vertical directions was measured on PDA medium containing cyproconazole, Rovral-TS, propiconazole or tebuconazole. The results of the analysis of variance revealed that the difference among various tested fungicides was significant $(p<0.01)$. Furthermore, data analysis showed the differences among fungicide concentrations, and among their interactions (fungicide $\times$ concentration) were significant at a $99 \%$ probability level.

Using Duncan's test, the comparison of the means of the fungicides' effects showed that maximum inhibition (67.3\%) of S. sclerotiorum (isolate No. 4) mycelial growth was obtained by tebuconazole (group A). Cyproconazole and propiconazole were ranked next with $65.49 \%$ and $65.04 \%$ inhibition, respectively (group B). Among the fungicides, Rovral-TS had the least effect on the growth of the isolate, with a $37.29 \%$ inhibition, as group C (Fig. 2A).

The mean comparison of the fungicide concentrations' effect on isolate 4 of S. sclerotiorum, showed that the maximum $(100 \%)$ growth inhibition was found at the highest dose, 1 ppm (group A). It was followed by the concentrations: $0.1,0.01,0.001$, and 0.0001 with 86.82 , $79.73,17.90$, and $9.45 \%$ inhibitions, respectively, as B, C, D, and E groups (Fig. 2B).

In studying the interaction effect (fungicide $\times$ concentration), a comparison of the means showed that maximum inhibition of $S$. sclerotiorum growth was obtained by the highest dose $(1 \mathrm{ppm})$ of all the tested fungicides, as well as by the doses of 0.1 and 0.01 ppm of propiconazole, cyproconazole, and tebuconazole, with $100 \%$ inhibition of growth (group A). The lowest dose (0.0001 ppm) of

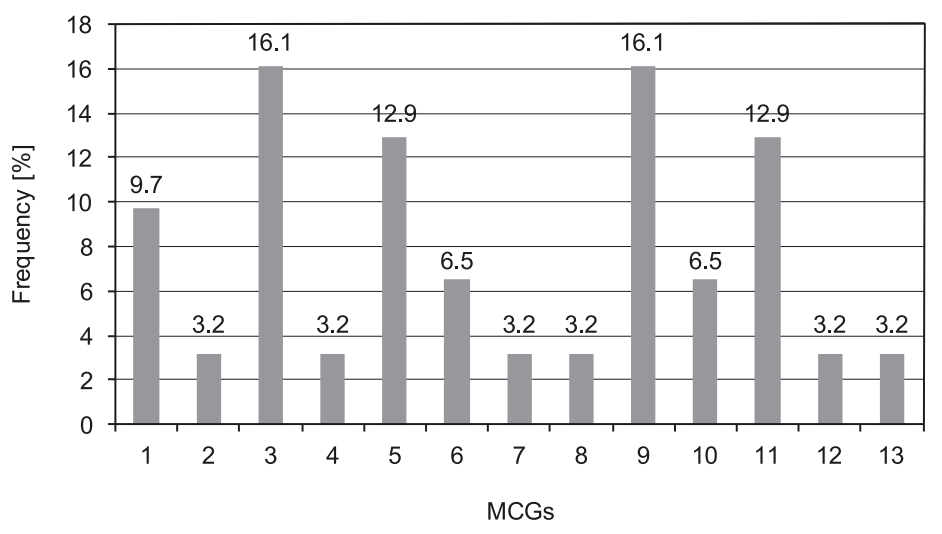

Fig. 1. Histogram of the frequencies of the 13 mycelial compatibility groups (MCGs) of Sclerotinia sclerotiorum from among 31 isolated strains. The number on each bar is the frequency of the respective MCG 

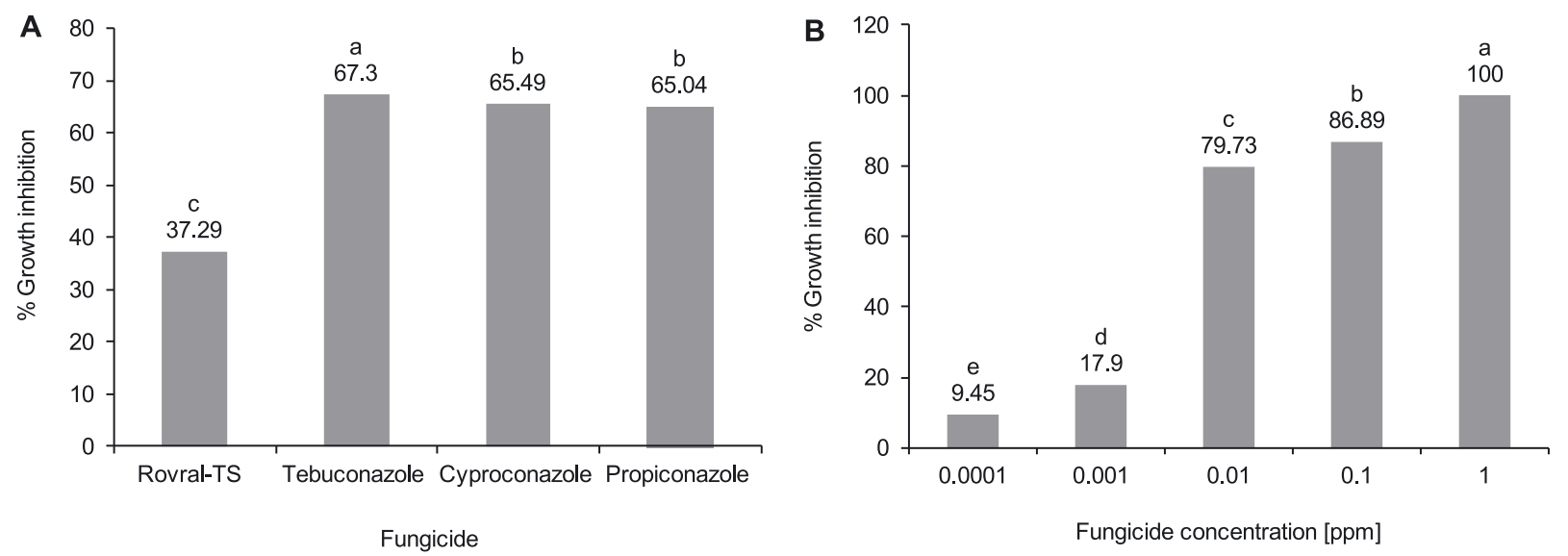

Fig. 2. Statistical grouping of selected fungicides (A) and concentrations (B) based on their effect on the growth inhibition of Sclerotinia sclerotiorum (Duncan's test, $\alpha=0.01$ ). The number on each bar is the growth inhibition of the respective fungicide (A) or the fungicide concentration (B). The letters on bars are related to significant or non-significant differences among the fungicides (A) or fungicide concentrations (B)

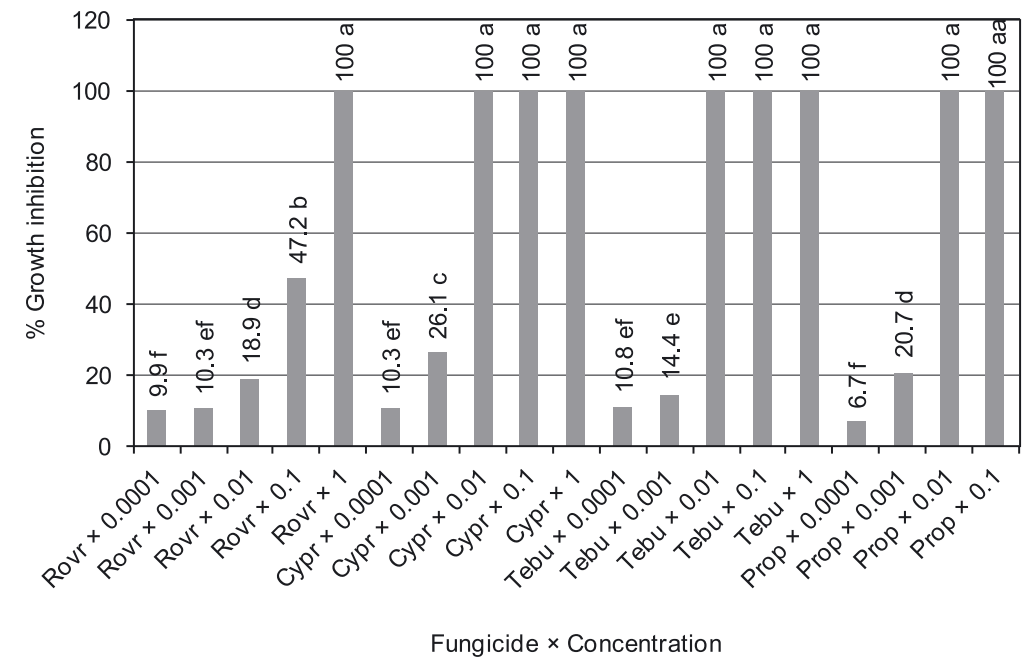

Fig. 3. Statistical grouping of selected fungicides $\times$ concentrations (interactions) based on their effect on the growth inhibition of Sclerotinia sclerotiorum (Duncan's test, $\alpha=0.01$ ). The number on each bar is the growth inhibition of the respective fungicide $x$ the concentration interaction. The letters on bars are related to significant or non-significant differences among the fungicide $x$ the concentration interactions. Rovr - Rovral-TS, Cypr - cyproconazole, Tebu - tebuconazole, Prop - propiconazole

propiconazole with $6.75 \%$ of inhibition was determined for group $\mathrm{F}$ (the least efficacy of fungicide $\times$ the concentration interaction on growth inhibition). Other treatments were between 6.75 and $100 \%$ of inhibition as groups B, C, D, and E (Fig. 3).

\section{Determination of $\mathrm{EC}_{50}$ for the fungicides tested against Sclerotinia sclerotiorum}

After measuring the radial mycelia growth in each plate, the linear regression for each fungicide was drawn using its concentrations and the inhibition percentages of growth (Fig. 4).

Using the equation of regression for tebuconazole $(y=10042 x+26.675)$, the fungicide concentration for $50 \%$ inhibition $\left(\mathrm{EC}_{50}\right)$ was calculated as $0.0023 \mathrm{ppm}$ (Fig. 4A). Similarly, by means of the regression equation for cyproconazole $(y=13087 x-1.774)$, propiconazole $(y=9857 x+16.791)$, and Rovral-TS $(y=79.668 x+22.012)$, the fungicide concentration for $50 \%$ inhibition $\left(\mathrm{EC}_{50}\right.$ ) was assessed as $0.0039,0.0034$, and 0.3513 ppm, respectively (Fig. 4B, C, and D).

\section{Effect of fungicides at their $\mathrm{EC}_{50}$ concentration on MCGs of Sclerotinia sclerotiorum}

Data about the effect of cyproconazole at its $\mathrm{EC}_{50}$ concentration on 13 MCGs of S. sclerotiorum showed this fungicide had the maximum (71.72\%) and minimum (6.69\%) effect on growth inhibition of MCG12 and MCG9 isolates, respectively (Table 2). The results showed that the effect of this fungicide on the growth inhibition of different MCGs was diverse (Fig. 5A) and significant (Table 2).

For Rovral-TS, the results showed a variable inhibition percentage between $4.29 \%$ and $69.34 \%$, respectively, for MCG11 and MCG12 isolates (Table 2). Notably, the majority $(\sim 70 \%)$ of MCGs were situated in the range of 4.29 to $23.59 \%$ growth inhibition (the dispersal of most 

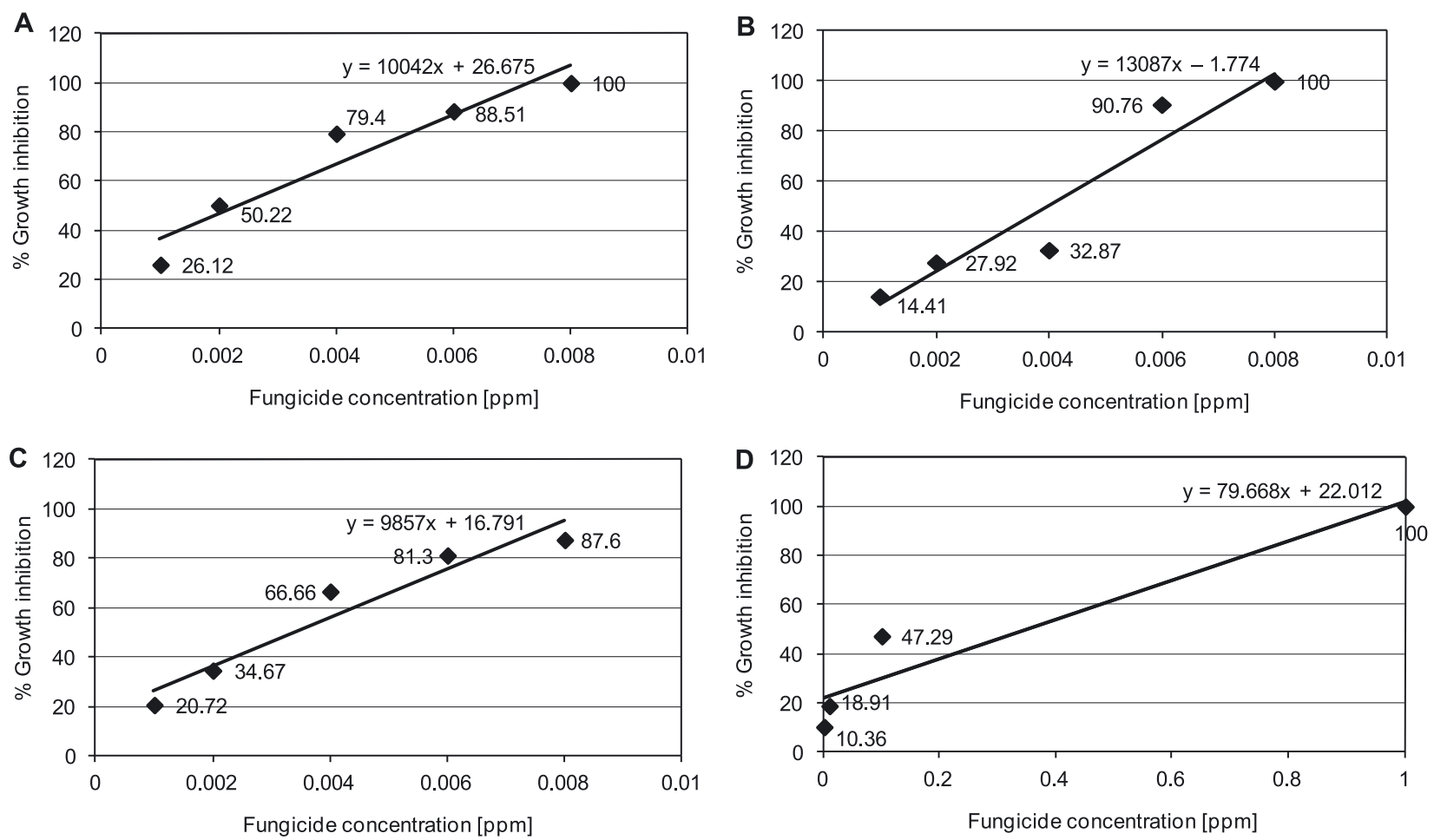

Fig. 4. The effect of different concentrations of the fungicides on the growth inhibition of Sclerotinia sclerotiorum mycelia, and their linear regression equations. The numbers near dots on the figures are the growth inhibitions of the respective fungicide concentrations: A - tebuconazole, B - cyproconazole, C - propioconazole, and D - Rovral-TS
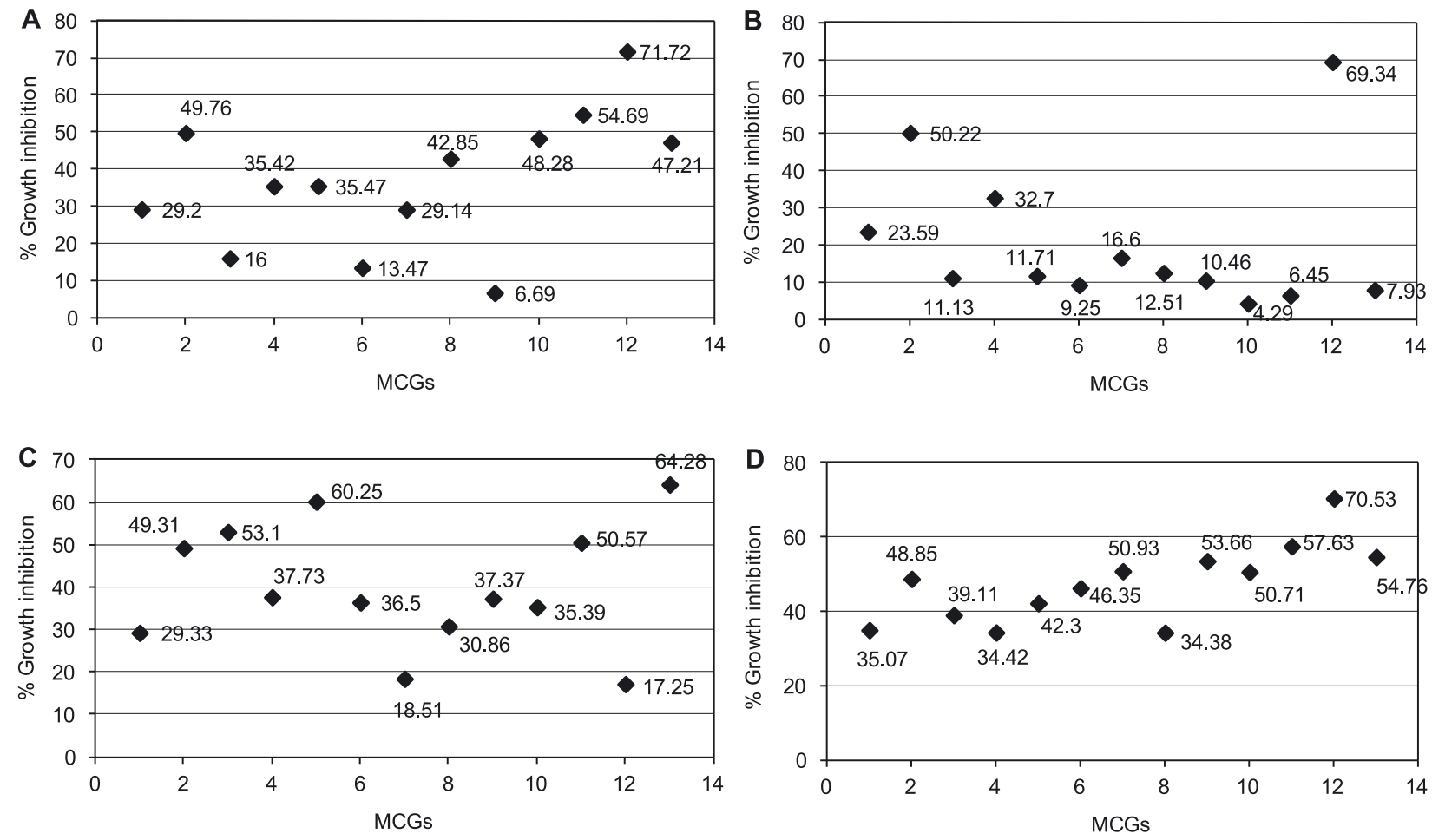

Fig. 5. The effect of cyproconazole (A), Rovral-TS (B), propiconazole (C), and tebuconazole (D) at their $\mathrm{EC}_{50}$ concentrations, on the growth inhibition of 13 mycelial compatibility groups (MCGs) of Sclerotinia sclerotiorum. The numbers near dots on the figures are the growth inhibitions of the respective MCGs

MCGs was in the narrow range, and so the reaction of most isolates to the latter fungicide was similar) (Fig. 5B). The presence of two types of chemicals (iprodion and carbendazim) in the formula of this fungicide is probably the reason of non-relative resistance against this product. In mixed fungicides (accompanied by two target point on fungi), the reduction of resistance to chemicals is the principal purpose, because an instant fungus cannot easily 
Table 2. Mean mycelial growth inhibitions ( \pm standard error) of the representatives of 13 mycelial compatibility groups (MCGs) of Sclerotinia sclerotiorum affected by different fungicides (at their $\mathrm{EC}_{50}$ concentrations)

\begin{tabular}{ccccc}
\hline MCGs & Cyproconazole & Rovral-TS & Propiconazole & Tebuconazole \\
\hline 1 & $29.20 \pm 0.38 \mathrm{e}$ & $23.59 \pm 2.1 \mathrm{~d}$ & $29.33 \pm 1.88 \mathrm{~d}$ & $35.07 \pm 1.73 \mathrm{~h}$ \\
2 & $49.76 \pm 2.09 \mathrm{bc}$ & $50.22 \pm 2.09 \mathrm{~b}$ & $49.31 \pm 1.37 \mathrm{~b}$ & $48.85 \pm 0.79 \mathrm{de}$ \\
3 & $16.00 \pm 2.97 \mathrm{f}$ & $11.13 \pm 1.19 \mathrm{ef}$ & $53.10 \pm 0.45 \mathrm{~b}$ & $39.11 \pm 2.50 \mathrm{gh}$ \\
4 & $35.42 \pm 3.69 \mathrm{de}$ & $32.70 \pm 2.18 \mathrm{c}$ & $37.73 \pm 3.27 \mathrm{c}$ & $34.42 \pm 1.09 \mathrm{~h}$ \\
5 & $35.47 \pm 2.96 \mathrm{~b}$ & $11.71 \pm 2.22 \mathrm{ef}$ & $60.25 \pm 1.93 \mathrm{a}$ & $42.30 \pm 2.75 \mathrm{fg}$ \\
6 & $13.47 \pm 1.68 \mathrm{f}$ & $9.25 \pm 1.83 \mathrm{fg}$ & $36.50 \pm 1.59 \mathrm{c}$ & $46.35 \pm 2.89 \mathrm{ef}$ \\
7 & $29.14 \pm 1.34 \mathrm{e}$ & $16.60 \pm 0.82 \mathrm{e}$ & $18.51 \pm 2.83 \mathrm{e}$ & $50.93 \pm 2.46 \mathrm{cde}$ \\
8 & $42.85 \pm 2.21 \mathrm{~cd}$ & $12.51 \pm 2.20 \mathrm{ef}$ & $30.86 \pm 2.44 \mathrm{~cd}$ & $34.38 \pm 1.83 \mathrm{~h}$ \\
9 & $6.69 \pm 1.47 \mathrm{f}$ & $10.46 \pm 1.36 \mathrm{efg}$ & $37.37 \pm 1.47 \mathrm{c}$ & $53.66 \pm 2.21 \mathrm{bcd}$ \\
10 & $48.28 \pm 2.60 \mathrm{bc}$ & $4.29 \pm 1.66 \mathrm{~g}$ & $35.39 \pm 2.49 \mathrm{~cd}$ & $50.71 \pm 2.19 \mathrm{cde}$ \\
11 & $54.69 \pm 2.70 \mathrm{~b}$ & $6.45 \pm 1.77 \mathrm{fg}$ & $50.57 \pm 1.77 \mathrm{~b}$ & $57.63 \pm 3.05 \mathrm{~b}$ \\
12 & $71.72 \pm 2.06 \mathrm{a}$ & $69.34 \pm 1.03 \mathrm{a}$ & $17.25 \pm 0.51 \mathrm{e}$ & $70.53 \pm 1.55 \mathrm{a}$ \\
13 & $47.21 \pm 2.77 \mathrm{bc}$ & $7.93 \pm 2.48 \mathrm{fg}$ & $64.28 \pm 2.38 \mathrm{a}$ & $54.76 \pm 2.38 \mathrm{bc}$ \\
\hline
\end{tabular}

Means within each column having the same letters are not significantly different (Duncan 1\%)

change two different pathways affected by a mixed fungicide. Determination of $\mathrm{EC}_{50}$ against isolate No. 4 (belonging to MCG2) with almost high sensitivity to Rovral-TS is probably the reason for the high percentage of isolates resistant to this chemical.

The effect of propiconazole at its $\mathrm{EC}_{50}$ concentration on the growth of 13 MCGs of S. sclerotiorum was significant (Table 2). Data showed that this fungicide had the minimum $(17.25 \%)$ effect on the growth inhibition of MCG12 (this is in opposite of the results obtained from the effect of two previous fungicides on MCG12). The maximum inhibition (64.28\%) was recorded on the MCG13 isolate. The results also showed the dispersal of MCGs was near uniform between minimum and maximum growth inhibition (Fig. 5C).

From among the tested fungicides, tebuconazole had the maximum effect on growth inhibition of MCG isolates of S. sclerotiorum. This chemical had the maximum $(70.53 \%)$ and minimum $(34.38 \%)$ effect on growth inhibition of MCG12 and MCG8 isolates, respectively (Table 2; Fig. 5D). Notably, the majority ( $82 \%$ ) of MCGs were situated in the 34.38 to $57.63 \%$ range of growth inhibition. It means most of the MCGs showed a nearly similar reaction to the fungicide.

\section{Discussion}

In northern Iran, Sclerotinia stem rot (SSR) is one of the most important diseases of canola. In this study, 13 MCGs were identified among 31 isolates of S. sclerotiorum sampled from four regions. It was found that common MCGs shared different fields. This may show movement of propagules or indicate selection for particular MCG genotypes affected by environmental conditions and competition (Kull et al. 2004). Furthermore, the results indicated a high level of MCG diversity. Genetic exchange, meiotic recombination (Carbone et al. 1999), mitotic recombination, transitory selection, selective neutrality, diversify- ing selection (Kohli et al. 1992), infrequent outbreeding in S. sclerotiorum, and immigration of strains from other sites (Glass and Kuldau 1992) could account for the possible sources of MCG diversity.

Different methods (e.g. cultural, biological, and chemical) have been used for control of the disease. Resistant plant cultivars accompanied by effective fungicides, are useful in the integrated management of the disease ( $\mathrm{Lu}$ 2003). Bradley et al. (2006) showed that the fungicides that consistently reduced SSR incidence were: azoxystrobin, benomyl, boscalid, iprodione, prothioconazole, tebuconazole, thiophanate-methyl, trifloxystrobin, and vinclozolin.

In the present work, the effect of some fungicides (tebuconazole, propiconazole, cyproconazole, and Rovral-TS) on the mycelial growth of S. sclerotiorum was studied. Tebuconazole was the most effective: $67.3 \%$ of growth inhibition. Cyproconazole, and propiconazole followed in subsequent degrees. Rovral-TS had a minimum effect (nearly half that of the other fungicides) on S. sclerotiorum. Tebuconazole, propiconazole, and cyproconazole showed $100 \%$ inhibition with the use of a concentration of $0.01 \mathrm{ppm}$, whereas $100 \%$ inhibition was obtained by 1 ppm of Rovral-TS. In this manner, $\mathrm{EC}_{50}$ for Rovral-TS was almost 100 times more than the $\mathrm{EC}_{50}$ for other mentioned fungicides. All these data indicate the insufficient efficiency of Rovral-TS as compared with the others when used to control S. sclerotiorum.

Also, the reaction of $S$. sclerotiorum isolates belonging to different MCGs against cyproconazole and propiconazole, was completely diverse; but their reaction to tebuconazole and Rovral-TS was closer. These results showed the high variation in Mazandaran isolates of S. sclerotiorum. The different reactions of some isolates (MCGs) to the chemicals of the same fungicidal group were interesting (e.g. the reaction of MCG9 isolate against cyproconazole, propiconazole and tebuconazole).

No shared MCGs or multilocus haplotypes were detected between two populations (United States and Chi- 
na) of S. sclerotiorum, and the populations differed significantly. Recombination was detected in both populations but was greater in the Chinese population. The two populations differed significantly for all of the phenotypic traits except for virulence (Attanayake et al. 2013).

Also, other studies indicated a high variation in S. sclerotiorum populations. Gossen et al. (2001) showed that the growth of 13 isolates of the fungus was inhibited by low concentrations of Benomyl $\left(\mathrm{EC}_{50}<8 \mathrm{mg} \cdot \mathrm{l}^{-1}\right)$, but two isolates were very resistant $\left(E_{50}>200 \mathrm{mg} \cdot \mathrm{l}^{-1}\right)$. In other work, the ranges of reduction in the radial growth of 91 isolates of S. sclerotiorum on PDA amended with thiophanate methyl and vinclozolin were 18 to $93 \%$ and 93 to $99 \%$, respectively (Mueller et al. 2002).

In the present study, the $\mathrm{EC}_{50}$ for the tested chemicals was recorded between 0.002 to $0.35 \mathrm{ppm}$, respectively, for tebuconazole and Rovral-TS. The $\mathrm{EC}_{50}$ values of carboxamide fungicides were recorded from 0.002 to $0.73 \mu \mathrm{g} \cdot \mathrm{ml}^{-1}$. The mean $\mathrm{EC}_{50}$ of iprodione (one of the Rovral-TS components) for wild-type isolates of S. sclerotiorum was reported as $0.43 \mathrm{ppm}$ (Liu et al. 2009). Qin et al. (2011) presented ten tested fungicides, including iprodione, carbendazim, and tebuconazole, which have an $\mathrm{EC}_{50}$ between 0.073 and $0.409 \mathrm{ppm}$. According to the sensitive determinations and the field-controlling effect, these substances may be used for effective prevention and control of S. sclerotiorum (Qin et al. 2011).

Like in the present study, the resistance to Rovral-TS was also reported by others. Out of a total of 1,890 tested isolates, 746 isolates were resistant to carbendazim (the other component of Rovral-TS) with the proportion of $39.5 \%$ by an $\mathrm{EC}_{50} 100 \mu \mathrm{g} \cdot \mathrm{ml}^{-1}$. But these resistant isolates were sensitive to triazole (as tebuconazole) group fungicides (Shi et al. 2000). Also, development of carbendazim resistance for the causal agent S. sclerotiorum was found widespread throughout Jiangsu Province (China) with a resistance frequency of $29.54 \%$ during the 2006 to 2008 growing seasons. The resistance frequencies differed among sampled cities, ranging from $3.1 \%$ to $54.9 \%$ (Ma et al. 2009). Fludioxonil-resistant mutants of S. sclerotiorum with resistance factors $\left(\mathrm{EC}_{50}\right.$ resistant/EC $\mathrm{E}_{50}$ sensitive phenotypes) $>2,000$ were also reported (Kuang et al. 2011). The $\mathrm{EC}_{50}$ values of the iprodione resistant isolates of the fungus were 200-fold higher than those of the original wild-type parents (Liu et al. 2009). Resistance to iprodione was also detected by Attanayake et al. (2013).

In conclusion, data from the present research show that mycelial growth of S. sclerotiorum was obviously affected by the application of different triazoles (especially tebuconazole) treatments. The fungistasis effect of tebuconazole on S. sclerotiorum is controlled by reducing mycelia dry weight, protein content, sclerotial germination and its pathogenicity, as mentioned by other researchers (Wang et al. 2010).

An instant fungicide does not have a similar effect on different populations of fungi, therefore, the rotation in chemical applications or mixed chemicals must be used to prevent the development of resistant strains. In the present study, such problems were introduced. Using less concentration of the chemicals is very important for environmental and human health. The least amount of a fun- gicide dose for application in the fields must be selected based on the dominant population of the causal disease agent present in each region. This topic was clearly highlighted in the present work.

The importance and reason of resistant populations of S. sclerotiorum to some of the mentioned chemicals (especially Rovral-TS) in the region, remains to be determined. Steel and Nair (1993) reported that resistance to iprodione (one of Rovral-TS component) may be mediated by altered levels of enzymes responsible for the detoxification of peroxy radicals formed by this fungicide.

\section{Acknowledgements}

The authors wish to thank Mazandaran Agricultural and Natural Resources Research and Education Center (AREEO) and Damghan Azad Islamic University for financial support of present work.

\section{References}

Attanayake R.N., Carter P.A., Jiang D., del Río-Mendoza L., Chen W. 2013. Sclerotinia sclerotiorum populations infecting canola from China and the United States are genetically and phenotypically distinct. Phytopathology 103 (7): 750-761.

Boland G.J., Hall R. 1994. Index of plant hosts of Sclerotinia sclerotiorum. Canadian Journal of Plant Pathology 16 (2): 93-108.

Bradley C.A., Lamey H.A., Endres G.J., Henson R.A., Hanson B.K., McKay K.R., Halvorson M., LeGare D.G., Porter P.M. 2006. Efficacy of fungicides for control of Sclerotinia stem rot of Canola. Plant Disease 90 (9): 1129-1134.

Brent K.J., Hollomon D.W. 2007. Fungicide Resistance in Crop Pathogens: How Can it be Managed? Fungicide Resistance Action Committee, Brussels, Belgium, 56 pp.

Carbone I., Anderson J.B., Kohn L.M. 1999. Patterns of descent in clonal lineages and their multilocus fingerprints are resolved with combined gene genealogies. Evolution 53 (1): $11-21$.

Duan Y., Ge C., Liu S., Chen C., Zhou M. 2013. Effect of phenylpyrrole fungicide fludioxonil on morphological and physiological characteristics of Sclerotinia sclerotiorum. Pesticide Biochemistry and Physiology 106 (1-2): 61-67.

Garg H., Sivasithamparam K., Banga S.S., Barbetti M.J. 2008. Cotyledon assay as a rapid and reliable method of screening for resistance against Sclerotinia sclerotiorum in Brassica napus genotypes. Australasian Plant Pathology 37 (2): 106-111.

Glass N.L., Kuldau G.A. 1992. Mating type and vegetative incompatibility in filamentous ascomycetes. Annual Review of Phytopathology 30: 201-224.

Glass N.L., Kaneko I. 2003. Fatal attraction: nonself recognition and heterokaryon incompatibility in filamentous fungi. Eukaryotic Cell 2 (1): 1-8.

Gossen B.D., Rimmer S.R., Holley J.D. 2001. First report of resistance to benomyl fungicide in Sclerotinia sclerotiorum. Plant Disease 85 (11): 1206.

Irani H., Heydari A., Javan-Nikkhah M., İbrahimov A.Ş. 2011. Pathogenicity variation and mycelial compatibility groups in Sclerotinia sclerotiorum. Journal of Plant Protection Research 51 (4): 329-336. 
Kohli Y., Morrall R.A.A., Anderson J.B., Kohn L.M. 1992. Local and trans-Canadian clonal distribution of Sclerotinia sclerotiorum on canola. Phytopathology 82 (8): 875-880.

Kohn L.M., Carbone I., Anderson J.B. 1990. Mycelial interactions in Sclerotinia sclerotiorum. Experimental Mycology 14 (3): 255-267.

Kuang J., Hou Y.P., Wang J.X., Zhou M.G. 2011. Sensitivity of Sclerotinia sclerotiorum to fludioxonil: In vitro determination of baseline sensitivity and resistance risk. Crop Protection 30 (7): 876-882.

Kull L.S., Pedersen W.L., Palmquist D., Hartman G.L. 2004. Mycelial compatibility grouping and aggressiveness of Sclerotinia sclerotiorum. Plant Disease 88 (4): 325-332.

Liu X., Yin Y., Yan L., Michailides T.J., Ma Z. 2009. Sensitivity to iprodione and boscalid of Sclerotinia sclerotiorum isolates collected from rapeseed in China. Pesticide Biochemistry and Physiology 95 (2): 106-112.

Lobato K.R., Cardoso C.C., Binfaré R.W., Budni J., Wagner C.L.R., Brocardo P.S., de Souza L.F., Brocardo C., Flesch S., Freitas A.E., Dafré A.L., Rodrigues A.L.S. 2010. $\alpha$-Tocopherol administration produces an antidepressant-like effect in predictive animal models of depression. Behavioural Brain Research 209 (2): 249-259.

Lu G. 2003. Engineering Sclerotinia sclerotiorum resistance in oilseed crops. African Journal of Biotechnology 2 (12): 509_ 516.

Ma H.X., Chen Y., Wang J.X., Yu W.Y., Tang Z.H., Chen C.J., Zhou M.G. 2009. Activity of carbendazim, dimethachlon, iprodione, procymidone and boscalid against Sclerotinia stem rot in Jiangsu province of China. Phytoparasitica 37 (5): 421-429.

Mueller D.S., Dorrance A.E., Derksen R.C., Ozkan E., Kurle J.E., Grau C.R., Gaska J.M., Hartman G.L., Bradley C.A., Pedersen W.L. 2002. Efficacy of fungicides on Sclerotinia sclerotio- rum and their potential for control of Sclerotinia stem rot on soybean. Plant Disease 86 (1): 26-31.

Pandey D.K., Tripathi N.N., Tripathi R.D., Dixit S.N. 1982. Fungitoxic and phytotoxic properties of the essential oil of Hyptis suaveolens. Zeitschrift für Pflanzenkrankheit und Pflanzenschutz 89 (6): 344-349.

Purdy L.H. 1979. Sclerotinia sclerotiorum: history, diseases and symptomatology, host range, geographic distribution, and impact. Phytopathology 69 (8): 875-880.

Qin H., Chen F., Fu D., Gao X., Huang L., Han Q., Kang Z., Xiong X., Zhang F. 2011. [Sensitivity of Sclerotinia sclerotiorium to 10 fungicides and controlling effect of different medicaments to the rape Sclerotinia stem rot in field]. Journal of Northwest A \& F University (Natural Science Edition) 39 (7): 117-122. (in Chinese, with English summary)

Schafer M.R., Kohn L.M. 2006. An optimized method for mycelial compatibility testing in Sclerotinia sclerotiorum. Mycologia 98 (4): 593-597.

Shi Z., Zhou M., Ye Z., Shi J., Chen H., Wang Y. 2000. [Resistance monitoring of Sclerotinia sclerotiorum to carbendazim]. Jiangsu Journal of Agricultural Sciences 16: 226-229. (in Chinese, with English summary)

Steel C.C., Nair N.G. 1993. The physiological basis of resistance to the dicarboximide fungicide iprodione in Botrytis cinerea. Pesticide Biochemistry and Physiology 47 (1): 60-68.

Wang C., Liu W., Ding S., Wang Z., Zhang Y. 2010. [Study on function of tebuconazole on Sclerotinia sclerotiorum]. Chinese Journal of Oil Crop Sciences 32 (3): 436-440. (in Chinese, with English summary)

Zhao J., Peltier A.J., Meng J., Osborn T.C., Grau C.R. 2004. Evaluation of Sclerotinia stem rot resistance in oilseed Brassica napus using petiole inoculation technique under greenhouse conditions. Plant Disease 88 (9): 1033-1039. 